\title{
Serum Gamma-Glutamyl Transferase Levels are Associated with Metabolic Syndrome in Community-Dwelling Individuals
}

\author{
Ryuichi Kawamoto ${ }^{1}$, Katsuhiko Kohara ${ }^{2}$, Yasuharu Tabara ${ }^{2}$, Tetsuro Miki², and Nobuyuki Otsuka ${ }^{1}$ \\ ${ }^{1}$ Department of Internal Medicine, Seiyo Municipal Nomura Hospital, Ehime, Japan \\ ${ }^{2}$ Department of Geriatric Medicine, Ehime University School of Medicine, Ehime, Japan
}

\begin{abstract}
Aim: Serum gamma-glutamyl transferase (GGT) activity changes in response to oxidative stress. Metabolic syndrome (MetS) is associated with an increased risk of major cardiovascular events. Few data are available on the association between serum GGT and the prevalence of MetS among community-dwelling individuals in Japan.

Methods: We recruited 793 men (mean age, $60 \pm 14$ years), and 1,073 women (62 \pm 12 years), free from any history relating to cardiovascular disease during their annual health examination, from a single community. We performed a cross-sectional study to examine whether serum GGT was associated with MetS.

Results: The levels of most confounding characteristics varied with increasing GGT activity. After adjustment for age, smoking status, drinking status, low-density lipoprotein cholesterol, uric acid, estimated glomerular filtration rate and alanine aminotransferase, the odds ratios $(95 \%$ confidence interval) for MetS increased across serum GGT tertiles (1, 2.23 (1.22-4.07), and $2.32(1.18-4.56)$ in men; and 1, $1.43(0.81-2.51)$, and $2.64(1.50-4.64)$ in women). After additional adjustment for insulin resistance markers (immuno-reactive insulin or homoeostasis model assessment of insulin resistance index), the association was attenuated and the linear relation no longer significant in both genders. Furthermore, serum GGT was significantly associated with the presence of individual components of MetS in both genders, except for dyslipidemia in men and hypertension in women.

Conclusions: These results suggested that higher serum GGT was significantly associated with MetS and its components in the general population. This association was related with insulin resistance but was independent of other confounding factors.
\end{abstract}

J Atheroscler Thromb, 2009; 16:355-362.

Key words; Gamma-glutamyl transferase, Metabolic syndrome, Risk factor, Insulin resistance

\section{Introduction}

Serum gamma-glutamyl transferase (GGT) is an enzyme that contributes to the extracellular catabolism of glutathione $(\mathrm{GSH})^{1)}$. The enzyme is present on cell surfaces and in serum, but most serum GGT is derived from the liver ${ }^{2}$. Serum GGT is a clinical marker of several factors: alcohol consumption, body fat content, plasma lipid/lipoproteins and glucose lev-

Address for correspondence: Ryuichi Kawamoto, Department of Internal Medicine, Seiyo Municipal Nomura Hospital, 9-53

Nomura, Nomura-cho, Seiyo-city, Ehime 797-1212, Japan

E-mail: rykawamo@yahoo.co.jp

Received: September 1, 2008

Accepted for publication: January 15, 2009 els, and medications ${ }^{1,2)}$. Elevated serum GGT activity is also a sensitive marker of oxidative stress ${ }^{1)}$ and is associated with cardiovascular disease (CVD) ${ }^{3-5)}$. Serum GGT can also reflect other concomitant risk factors, such as obesity ${ }^{6}$, insulin resistance ${ }^{7,8)}$, diabetes ${ }^{7-10)}$, hypertension ${ }^{9,11)}$, and dyslipidemia and metabolic syndrome $^{10,12-14)}$

Metabolic syndrome (MetS), a clustering of cardiovascular risk factors such as insulin resistance, hypertension, glucose intolerance, hypertriglyceridemia, and low high-density lipoprotein cholesterol (HDL-C) levels, is a major worldwide public health problem. MetS affects $13.3 \%$ to $24.4 \%$ of Japanese men $\geq 30$ years of age ${ }^{15,16}$. With the continuous increase in obesity prevalence in Japan, MetS may become even more 
common. MetS increases the risk of atherosclerotic disease, diabetes ${ }^{17,}{ }^{18)}$, and $\mathrm{CVD}^{19)}$; however, there are few reports on the relationship between serum GGT and MetS in Japan.

The aim of this study was to determine whether serum GGT is associated with MetS risk, and we examined cross-sectional data from Japanese community-dwelling participants.

\section{Materials and Methods}

\section{Subjects}

Participants were recruited at the time of their annual health examination in a rural town with a total population of 11,136 (as of April 2002) located in Ehime prefecture, Japan, in 2002. Among 9,133 adults aged 19 to 90 years in this population, 3,164 (34.6\%) were assessed for eligibility to participate in the study. Information on medical history, present conditions, and medications was obtained by interview. The final study sample included 1,866 eligible individuals free from any history or symptoms of CVD. The Ethics Committee of Ehime University School of Medicine approved all procedures.

\section{Evaluation of Risk Factors}

Information on demographic characteristics and risk factors was collected using clinical files. Body mass index was calculated by dividing weight (in kilograms) by the square of the height (in meters). We measured blood pressure with an appropriately sized cuff on the right upper arm of the subjects using an automatic oscillometric blood pressure recorder (BP103i; Colin, Aichi, Japan) while seated after resting for at least $5 \mathrm{~min}$. Cigarette smoking was quantified based on daily consumption and a history of smoking for subjects who reported smoking. Total cholesterol (T-C), triglycerides (TG), HDL-C, fasting blood glucose (FBG), creatinine (enzymatic method), uric acid, immuno-reactive insulin (IRI), alanine aminotransferase (ALT), and GGT were measured during fasting. Serum GGT concentration was assayed with an automatic analyzer (TBA-c6000, TOSHIBA, Tokyo) and the intraassay coefficient of variation was 0.87 to $2.11 \%$. Low-density lipoprotein cholesterol (LDL-C) was calculated by the Friedewald formula ${ }^{20)}$. Participants with $\mathrm{TG} \geq 400 \mathrm{mg} / \mathrm{dL}$ were excluded (34 cases). Estimated GFR was calculated using the following equation: $\mathrm{eGFR}=194 \times \mathrm{Cr}^{-1.094} \times \mathrm{Age}^{-0.287} \times 0.739$ (if female $)^{21)}$. Participants with an eGFR $<30 \mathrm{~mL} / \mathrm{min} /$ $1.73 \mathrm{~m}^{2}$ were excluded (8 cases). Homeostasis of minimal assessment of insulin resistance (HOMA-IR) was calculated from FBG and IRI levels using the follow- ing formula; FBG $\{(\mathrm{mg} / \mathrm{dL}) \times \mathrm{IRI}(\mathrm{mU} / \mathrm{mL})\} / 405^{22)}$.

\section{Metabolic Syndrome}

We applied condition-specific cutoff points for MetS based on the modified guidelines for the diagnosis of MetS in Japan ${ }^{23)}$. Metabolic syndrome was defined as obesity with at least two of the following three conditions: hypertension, dyslipidemia, and impaired fasting glucose (IFG). Obesity was defined as a BMI $\geq 25.0 \mathrm{~kg} / \mathrm{m}^{2} 24,25$. Hypertension was defined as systolic blood pressure $(\mathrm{SBP}) \geq 130 \mathrm{mmHg}$, diastolic blood pressure (DBP) $\geq 85 \mathrm{mmHg}$, or current treatment for hypertension. Dyslipidemia was defined as TG concentrations $\geq 150 \mathrm{mg} / \mathrm{dL}$, low HDL cholesterolemia (HDL-C $<40 \mathrm{mg} / \mathrm{dL}$ ), or current treatment for dyslipidemia. IFG was defined as a FBG level $\geq 110$ $\mathrm{mg} / \mathrm{dL}$ or current treatment for diabetes mellitus.

\section{Statistical Analysis}

Statistical analyses were performed using SPSS 10.0J (Statistical Package for Social Science, Inc., Chicago, IL, USA). Data are presented as the mean \pm standard deviation (SD) unless otherwise specified, and parameters with non-normal distributions (TG, ALT, IRI, HOMA-IR, and GGT), the data are the median (interquartile range). In all analyses, parameters with non-normal distributions were used after log transformation. Differences among 3 groups divided based on tertiles of serum GGT (12-27 IU/L, 28-54 IU/L and $\geq 55 \mathrm{IU} / \mathrm{L}$ in men; and 9-17 IU/L, 18-24 IU/L and $\geq 25$ IU/L in women) were analyzed by the MannWhitney $U$ test, Kruskal-Wallis test or chi-square $\left(\chi^{2}\right)$ test. Multiple logistic regression analysis was used to evaluate the contribution of confounding factors for $\mathrm{MetS}$ and each component of MetS. A $p$-value $<0.05$ was considered significant.

\section{Results}

\section{Subject Background Characteristics}

The characteristics of the study participants in relation to sex are illustrated in Table 1 . The study included 793 men, aged $60 \pm 14$ (range, 20-89) years, and 1,073 women, aged $62 \pm 12$ (range, 21-88) years. Body mass index, smoking status, drinking status, SBP, DBP, TG, uric acid, ALT, FBG, and GGT were higher in men than in women, but age, HDL-C, LDL-C, antilipidemic medication, IRI, and HOMA-IR were higher in women. There was no inter-group difference in antihypertensive medication, eGFR, and diabetic medication. 
Table 1. Characteristics of subjects categorized according to sex

\begin{tabular}{|c|c|c|c|}
\hline Characteristics & $\operatorname{Men}(n=793)$ & Women $(n=1,073)$ & $p$-value* \\
\hline Age (years) & $60 \pm 14$ & $62 \pm 12$ & 0.001 \\
\hline Body mass index $\left(\mathrm{kg} / \mathrm{m}^{2}\right)$ & $23.6 \pm 3.0$ & $23.3 \pm 3.4$ & 0.044 \\
\hline Smoking status, N (\%) & $456(57.5)$ & $27(2.5)$ & $<0.001$ \\
\hline Drinking status, N (\%) & $691(87.1)$ & $384(35.8)$ & $<0.001$ \\
\hline Systolic blood pressure (mmHg) & $140 \pm 21$ & $138 \pm 24$ & 0.043 \\
\hline Diastolic blood pressure (mmHg) & $84 \pm 11$ & $80 \pm 12$ & $<0.001$ \\
\hline Antihypertensive medication, N (\%) & $183(23.1)$ & $260(24.2)$ & 0.582 \\
\hline Triglycerides (mg/dL) & $98(72-140)$ & $90(67-125)$ & $<0.001$ \\
\hline HDL cholesterol (mg/dL) & $59 \pm 15$ & $65 \pm 15$ & $<0.001$ \\
\hline LDL cholesterol (mg/dL) & $111 \pm 32$ & $126 \pm 30$ & $<0.001$ \\
\hline Antilipidemic medication, N (\%) & $27(3.4)$ & $66(6.2)$ & 0.007 \\
\hline Serum uric acid (mg/dL) & $5.9 \pm 1.4$ & $4.5 \pm 1.1$ & $<0.001$ \\
\hline Estimated GFR $\left(\mathrm{mL} / \mathrm{min} / 1.73 \mathrm{~m}^{2}\right)$ & $81.8 \pm 17.0$ & $80.3 \pm 17.3$ & 0.077 \\
\hline Alanine aminotransferase (IU/L) & $21(16-28)$ & $15(12-20)$ & $<0.001$ \\
\hline Immuno-reactive insulin (mU/mL) & $4.6(3.0-7.3)$ & $6.0(4.1-8.6)$ & $<0.001$ \\
\hline HOMA-IR ${ }^{*}$ & $1.1(0.9-1.8)$ & $1.4(0.9-2.0)$ & $<0.001$ \\
\hline Fasting blood glucose (mg/dL) & $101 \pm 23$ & $96 \pm 19$ & $<0.001$ \\
\hline Diabetic medication, N (\%) & $27(3.4)$ & $34(3.2)$ & 0.793 \\
\hline Gamma-glutamyl transferase (IU/L) & $38(25-69)$ & $20(16-28)$ & $<0.001$ \\
\hline
\end{tabular}

Data presented are the mean \pm standard deviation. Data for triglycerides, alanine aminotransferase, insulin, HOMA-IR, and gammaglutamyl transferase were skewed and are presented as the median (interquartile range). ${ }^{*}$ Homeostasis of minimal assessment of insulin resistance (HOMA-IR) was calculated using the following formula: fasting blood glucose $\{(\mathrm{mg} / \mathrm{dL}) \times \operatorname{IRI}(\mathrm{mU} / \mathrm{mL})\} / 405$. HDL, high-density lipoprotein; LDL, low-density lipoprotein; GFR, glomerular filtration rate. Estimated GFR $=194 \times \mathrm{Cr}^{-1.094} \times \mathrm{Age}^{-0.287} \times$ 0.739 (if female). * $p$-value for comparison between men and women: Mann-Whitney $U$ test or $\chi^{2}$ test.

\section{Relationship between Clinical Characteristics and Tertiles of Serum GGT}

As shown in Table 2, tests for differences in characteristics across the three serum GGT levels were significant, except for the prevalence of antihypertensive and diabetic medications in both genders, and for age, smoking status, drinking status, and eGFR in women. In both genders, LDL-C, uric acid, ALT, IRI, HOMA-IR, BMI, DBP, TG, and FBG showed a linear trend in relation to serum GGT Men in higher GGT tertiles were younger, smokers, drinkers, and had elevated eGFR. HDL-C showed a U-shaped association with serum GGT in men and a downward trend in women. Women in higher GGT tertiles had elevated SBP, and a prevalence toward antilipidemic medication.

\section{Relationship between HOMA-IR and Serum GGT}

HOMA-IR significantly increased in correlation with an increase in serum GGT in both men $(r=$ $0.275)$ and women $(r=0.337)$ (Fig. 1).

\section{Odds Ratio for MetS According to Tertiles of Serum GGT}

Table 3 shows the risk of MetS in relation to serum GGT among 793 men and 1,073 women. Of these, 125 men (15.8\%) and 137 women (12.8\%) had MetS. In both genders, the prevalence of MetS significantly increased in relation to serum GGT. After adjustment for age, smoking status, drinking status, LDL-C, uric acid, eGFR, and ALT, the odds ratio for MetS was 1.00, 2.23 (95\% CI, 1.22-4.07), and 2.32 (95\% CI, 1.18-4.56) in men, and 1.00, $1.43(95 \%$ CI, 0.81-2.51), and 2.64 (95\% CI, $1.50-4.64)$ in women, respectively. After additional adjustment for insulin resistance markers (IRI or HOMA-IR), the association was attenuated and the linear relation no longer significant in either gender.

\section{Odds Ratio for Individual Components of MetS According to Tertiles of Serum GGT}

The prevalence of individual components of MetS was significantly and linearly associated with increasing tertiles of serum GGT in both genders (Table 4). After adjustment for age, smoking status, drinking status, LDL-C, uric acid, eGFR, and ALT, 
Table 2. Characteristics of various risk factors and metabolic syndrome components of subjects categorized by sex and serum gamma-glutamyl transferase

\begin{tabular}{|c|c|c|c|c|c|c|c|c|}
\hline \multirow[b]{2}{*}{ Characteristics } & \multicolumn{4}{|c|}{ Men, $n=793$} & \multicolumn{4}{|c|}{ Women, $n=1,073$} \\
\hline & $\begin{array}{c}\text { GGT-1 } \\
12-27 \text { IU/L } \\
n=257 \\
\mathrm{~N}(\%)\end{array}$ & $\begin{array}{c}\text { GGT-2 } \\
28-54 \mathrm{IU} / \mathrm{L} \\
n=275 \\
\mathrm{~N}(\%)\end{array}$ & $\begin{array}{c}\text { GGT-3 } \\
\begin{array}{c}\geq 55 \mathrm{IU} / \mathrm{L} \\
n=261 \\
\mathrm{~N}(\%)\end{array}\end{array}$ & $\begin{array}{l}p \text { for } \\
\text { trend }\end{array}$ & $\begin{array}{c}\text { GGT-1 } \\
\begin{array}{c}9-17 \mathrm{IU} / \mathrm{L} \\
n=379 \\
\mathrm{~N}(\%)\end{array}\end{array}$ & $\begin{array}{c}\text { GGT-2 } \\
18-24 \mathrm{IU} / \mathrm{L} \\
n=352 \\
\mathrm{~N}(\%)\end{array}$ & $\begin{array}{c}\text { GGT-3 } \\
\begin{array}{c}25 \mathrm{IU} / \mathrm{L} \\
n=342 \\
\mathrm{~N}(\%)\end{array}\end{array}$ & $\begin{array}{l}p \text { for } \\
\text { trend }^{*}\end{array}$ \\
\hline \multicolumn{9}{|l|}{ Other confounding factors } \\
\hline Age (years) & $64 \pm 15$ & $60 \pm 13$ & $55 \pm 12$ & $<0.001$ & $61 \pm 13$ & $63 \pm 11$ & $63 \pm 10$ & 0.534 \\
\hline Smoking status, N (\%) & $122(47.5)$ & $157(57.1)$ & $177(67.8)$ & 0.001 & $5(1.3)$ & $8(2.3)$ & $14(4.1)$ & 0.056 \\
\hline Drinking status, N (\%) & $205(79.8)$ & $235(85.5)$ & $251(96.2)$ & $<0.001$ & $140(36.9)$ & $114(32.4)$ & $130(38.0)$ & 0.256 \\
\hline LDL cholesterolemia $(\mathrm{mg} / \mathrm{dL})$ & $114 \pm 28$ & $113 \pm 30$ & $105 \pm 36$ & 0.003 & $119 \pm 27$ & $128 \pm 28$ & $132 \pm 32$ & $<0.001$ \\
\hline Uric acid (mg/dL) & $5.4 \pm 1.3$ & $5.9 \pm 1.3$ & $6.4 \pm 1.4$ & $<0.001$ & $4.2 \pm 1.0$ & $4.5 \pm 1.0$ & $4.8 \pm 1.1$ & $<0.001$ \\
\hline eGFR (mL/min/1.73 $\left.\mathrm{m}^{2}\right)$ & $79.8 \pm 17.5$ & $81.0 \pm 15.0$ & $84.6 \pm 18.2$ & 0.001 & $80.7 \pm 17.1$ & $79.5 \pm 17.3$ & $80.7 \pm 17.5$ & 0.784 \\
\hline Alanine aminotransferase (IU/L) & $16(13-21)$ & $20(16-25)$ & $29(21-38)$ & $<0.001$ & $13(11-16)$ & $15(13-18)$ & $21(16-28)$ & $<0.001$ \\
\hline Immuno-reactive insulin (mU/mL) & $3.7(2.3-5.8)$ & $4.8(3.2-7.3)$ & $5.5(3.8-8.5)$ & $<0.001$ & $5.0(3.6-6.6)$ & $6.0(4.2-8.6)$ & $7.7(5.1-10.7)$ & $<0.001$ \\
\hline HOMA-IR & $0.8(0.5-1.4)$ & $1.2(0.8-1.9)$ & $1.5(0.9-2.2)$ & $<0.001$ & $1.1(0.8-1.5)$ & $1.4(1.0-2.0)$ & $1.8(1.2-2.7)$ & $<0.001$ \\
\hline \multicolumn{9}{|l|}{ Metabolic syndrome component } \\
\hline Body mass index $\left(\mathrm{kg} / \mathrm{m}^{2}\right)$ & $22.5 \pm 2.6$ & $23.8 \pm 2.9$ & $24.4 \pm 3.1$ & $<0.001$ & $22.4 \pm 2.8$ & $23.4 \pm 3.4$ & $24.4 \pm 3.5$ & $<0.001$ \\
\hline Systolic blood pressure (mmHg) & $138 \pm 22$ & $140 \pm 21$ & $141 \pm 19$ & 0.084 & $135 \pm 24$ & $138 \pm 23$ & $140 \pm 24$ & 0.030 \\
\hline Diastolic blood pressure (mmHg) & $81 \pm 11$ & $84 \pm 11$ & $87 \pm 11$ & $<0.001$ & $78 \pm 12$ & $80 \pm 12$ & $82 \pm 12$ & 0.001 \\
\hline Antihypertensive medication, N (\%) & $58(22.6)$ & $65(23.6)$ & $60(23.0)$ & 0.957 & $70(18.5)$ & $98(27.8)$ & $92(26.9)$ & 0.814 \\
\hline Triglycerides (mg/dL) & $82(63-110)$ & $100(75-136)$ & $118(83-180)$ & $<0.001$ & $83(62-109)$ & $88(66-120)$ & $103(77-150)$ & $<0.001$ \\
\hline HDL cholesterol (mg/dL) & $58 \pm 14$ & $57 \pm 14$ & $61 \pm 17$ & 0.023 & $65 \pm 15$ & $66 \pm 15$ & $63 \pm 16$ & 0.027 \\
\hline Antilipidemic medication, N (\%) & $6(2.3)$ & $14(5.1)$ & $7(2.7)$ & 0.158 & $11(2.9)$ & $19(5.4)$ & $36(10.5)$ & $<0.001$ \\
\hline Fasting blood glucose (mg/dL) & $95 \pm 16$ & $100 \pm 19$ & $106 \pm 30$ & $<0.001$ & $91 \pm 11$ & $97 \pm 19$ & $101 \pm 24$ & $<0.001$ \\
\hline Diabetic medication, N (\%) & $11(4.3)$ & $7(2.5)$ & $9(3.4)$ & 0.544 & $8(2.1)$ & $10(2.8)$ & $16(4.7)$ & 0.132 \\
\hline
\end{tabular}

Data presented are the mean \pm standard deviation. Data for triglycerides, alanine aminotransferase, imuno-reactive insulin, and HOMA-IR were skewed and are presented as median (interquartile range). Metabolic syndrome: component conditions of the metabolic syndrome defined as obesity and two of the following conditions: hypertension, dyslipidemia and impaired fasting blood glucose. LDL, low-density lipoprotein; HOMA-IR, homeostasis of minimal assessment of insulin resistance; GGT, gamma-glutamyl transferase. * $p$ : Kruskal-Wallis test or $\chi^{2}$ test.

serum GGT was significantly associated with the presence of individual components of MetS in both genders, except for dyslipidemia in men and hypertension in women.

\section{Discussion}

In this cross-sectional, population-based study, we determined the prevalence of MetS, as defined by modified Japanese criteria ${ }^{23)}$, and examined the association between serum GGT and MetS and its components. MetS was common, occurring in $15.8 \%$ of men and $12.8 \%$ of women. Serum GGT levels were significantly associated with a risk for MetS and its components, except for dyslipidemia in men and hypertension in women, even after adjusting for age, smoking status, drinking status, LDL-C, uric acid, eGFR, and ALT. The OR of MetS dose-dependently increased from the upper normal range with increasing tertiles

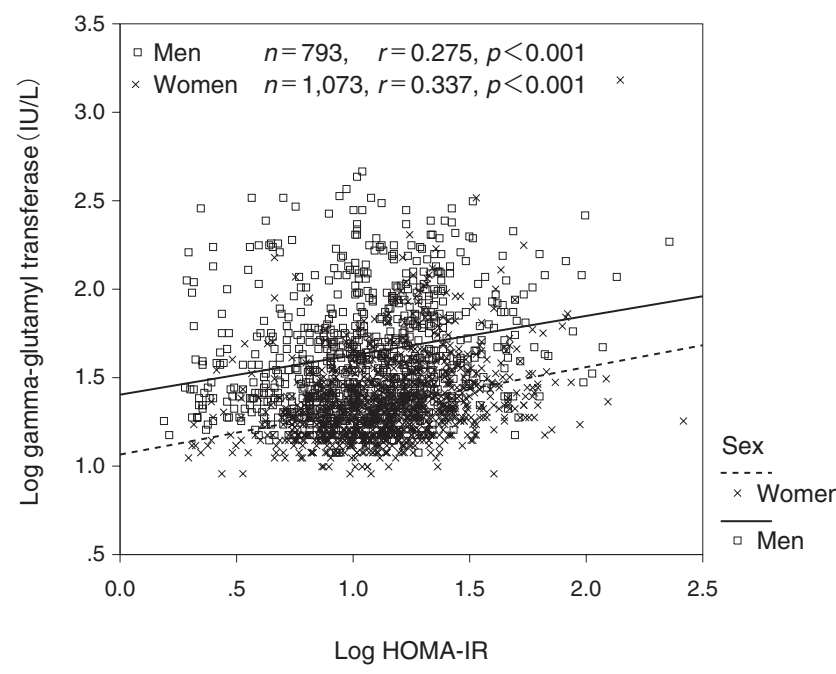

Fig. 1. Relationship between HOMA-IR and gamma-glutamyl transferase HOMA-IR, homeostasis of minimal assessment of insulin resistance. 
Table 3. Odds ratio $(95 \% \mathrm{CI})$ for metabolic syndrome according to tertiles of serum gamma-glutamyl transferase

\begin{tabular}{|c|c|c|c|c|c|c|c|c|}
\hline & \multicolumn{4}{|c|}{ Men, $n=793$} & \multicolumn{4}{|c|}{ Women, $n=1,073$} \\
\hline Cases, N (\%) & $18(7.0)$ & $47(17.1)$ & $60(23.0)$ & $<0.001$ & $22(5.8)$ & $36(10.2)$ & $79(23.1)$ & $<0.001$ \\
\hline \multicolumn{9}{|l|}{ Model 1} \\
\hline \multicolumn{9}{|l|}{ Model 2} \\
\hline $\begin{array}{l}\text { Odds ratio } \\
(95 \% \mathrm{CI})\end{array}$ & 1.00 & $\begin{array}{c}2.67 \\
(1.50-4.73)\end{array}$ & $\begin{array}{c}3.70 \\
(2.09-6.55)\end{array}$ & $<0.001$ & 1.00 & $\begin{array}{c}1.80 \\
(1.04-3.13)\end{array}$ & $\begin{array}{c}4.82 \\
(2.93-7.95)\end{array}$ & $<0.001$ \\
\hline \multicolumn{9}{|l|}{ Model 3} \\
\hline $\begin{array}{l}\text { Odds ratio } \\
(95 \% \mathrm{CI})\end{array}$ & 1.00 & $\begin{array}{c}2.23 \\
(1.22-4.07)\end{array}$ & $\begin{array}{c}2.32 \\
(1.18-4.56)\end{array}$ & 0.016 & 1.00 & $\begin{array}{c}1.43 \\
(0.81-2.51)\end{array}$ & $\begin{array}{c}2.64 \\
(1.50-4.64)\end{array}$ & 0.001 \\
\hline \multicolumn{9}{|l|}{ Model 5} \\
\hline $\begin{array}{l}\text { Odds ratio } \\
(95 \% \mathrm{CI})\end{array}$ & 1.00 & $\begin{array}{c}1.66 \\
(0.88-3.13)\end{array}$ & $\begin{array}{c}1.63 \\
(0.81-3.30)\end{array}$ & 0.259 & 1.00 & $\begin{array}{c}0.92 \\
(0.50-1.71)\end{array}$ & $\begin{array}{c}1.53 \\
(0.82-2.86)\end{array}$ & 0.133 \\
\hline
\end{tabular}

Metabolic syndrome: component conditions of the metabolic syndrome defined as obesity and two of the following conditions: hypertension, dyslipidemia and impaired fasting blood glucose. Model 1: non-adjusted; Model 2: adjusted for age; model 3: adjusted for age, smoking status, drinking status, low-density lipoprotein cholesterol, uric acid, estimated glomerular filtration rate, and log alanine aminotransferase; model 4: adjusted as described for model 2 plus log immuno-reactive insulin; model 5: adjusted as described for model 2 plus log homeostasis of minimal assessment of insulin resistance. GGT, gamma-glutamyl transferase.

Table 4. Adjusted odds ratio (95\% CI) for each metabolic syndrome component according to tertiles of serum gamma-glutamyl transferase

\begin{tabular}{|c|c|c|c|c|c|c|c|c|}
\hline Characteristics & \multicolumn{4}{|c|}{ Men, $n=793$} & \multicolumn{4}{|c|}{ Women, $n=1,073$} \\
\hline \multicolumn{9}{|l|}{ Obesity } \\
\hline Cases, N (\%) & $36(14.0)$ & $90(32.7)$ & $107(41.0)$ & $<0.001$ & $63(16.6)$ & $102(29.0)$ & $144(42.1)$ & $<0.001$ \\
\hline \multicolumn{9}{|l|}{ Hypertension } \\
\hline Cases, N (\%) & $161(62.6)$ & $202(73.5)$ & $192(73.6)$ & 0.008 & $226(59.6)$ & $235(66.8)$ & $228(66.7)$ & 0.069 \\
\hline Adjusted odds ratio $(95 \% \mathrm{CI})$ & 1.00 & $2.32(1.49-3.59)$ & $2.99(1.77-5.07)$ & $<0.001$ & 1.00 & $1.10(0.77-1.57)$ & $0.82(0.55-1.23)$ & 0.327 \\
\hline \multicolumn{9}{|l|}{ Dyslipidemia } \\
\hline Cases, N (\%) & $53(20.6)$ & $69(25.1)$ & $104(39.8)$ & $<0.001$ & $64(16.9)$ & $80(22.7)$ & $134(39.2)$ & $<0.001$ \\
\hline
\end{tabular}

Adjusted for age, smoking status, drinking status, low density lipoprotein cholesterol, uric acid, and estimated glomerular filtration rate and log alanine aminotransferase. 
of serum GGT. In addition, we demonstrated gender differences in MetS components with which serum GGT was independently associated.

In our study, higher GGT levels were positively associated with MetS, independent of other confounders. Similar results were found in a community-based cross-sectional study of 1,024 Caucasian adults, aged 40 to 59 years, in Finland ${ }^{12)}$. Elevated GGT may not always relate to alcohol consumption, but may also indicate the existence of $\mathrm{Met} \mathrm{S}^{12}$. In a pooled logistic analysis after adjustment for age, BMI, alcohol consumption, and gender, serum GTT (log-transformed GGT odds ratio 4.0, 95\% CI 2.80-5.69) as well as BMI, uric acid, and T-C were independent contributors of $\mathrm{Met} \mathrm{S}^{12)}$. Moreover, Nakanishi et al. ${ }^{10)}$ also demonstrated that serum GGT may be an important predictor for developing MetS in 2,957 metabolic syndrome-free men and 3,260 nondiabetic men aged 35-59 years. After adjustment for age, family history of diabetes, BMI, alcohol intake, smoking status, regular physical activity, and white blood cell count, increased serum GGT was related to the risk of developing MetS, even among individuals with normal GGT concentrations, a finding consistent with previous prospective reports looking at GGT ${ }^{10,14)}$.

Serum GGT is a sensitive indicator of alcohol consumption and/or liver dysfunction, such as fatty liver ${ }^{1)}$, and is also high in patients with liver disease: chronic viral hepatitis, primary biliary cirrhosis (PBC), or drug induced liver injury. These liver diseases are present in community-dwelling individuals and are usually asymptomatic ${ }^{26}$; hence, our study participants might Include patients with subclinical liver diseases. Nevertheless, the influence of these liver diseases might be small because patients with $\mathrm{PBC}$ were rare ${ }^{26)}$, and those with viral hepatitis had already been identified during their annual health examination and treated. Further, the relationships between serum GGT and MetS persisted after adjusting for ALT. Of our enrolled patients, $87.1 \%$ of men and $35.8 \%$ of women drank alcohol, but MetS prevalence was similar in both genders, and the association between serum GGT and MetS persisted after adjusting for alcohol drinking; therefore, GGT may be an important biomarker for evaluating MetS risk.

In our study, serum GGT was significantly associated with the presence of individual components of $\mathrm{MetS}$ in both genders, excepting for dyslipidemia in men and hypertension in women, and was significantly lower in women than in men. It has been shown that the higher the baseline GGT level, the stronger the effect of age on the development of hypertension $^{27)}$; thus, the well-described association between serum GGT and blood pressure might not be significant in women. Furthermore, serum GGT has also been shown to be more associated with hypertriglyceridemia and abnormal glucose tolerance among components of MetS, suggesting that serum GGT has a closer relationship with hepatic insulin resistance ${ }^{13,28)}$. In this study, serum GGT in men was not associated with dyslipidemia after adjustment; however serum GGT was significantly correlated with TG in multivariate analysis (data not shown).

The mechanisms by which GGT reflects the risk for MetS are not completely understood. Serum GGT was strongly associated with hypertension, dyslipidemia, and abnormal glucose tolerance, suggesting that elevated serum GGT accompanies hepatic insulin resistance, regardless of the presence of non-alcoholic fatty liver disease ${ }^{28-30)}$. In our study, serum GGT levels were strongly associated with HOMA-IR, which is a reliable marker of insulin resistance, and after additional adjustment for HOMA-IR, the association between serum GGT and MetS was attenuated. Elevated GGT may also reflect inflammation, which impairs insulin signaling in the liver, muscle, and adipose tissues ${ }^{31)}$. Fat accumulation in the liver or adipose tissues can induce inflammatory cytokines, such as tumor necrosis factor- $\alpha$, interleukin- 6 , and interleukin- ${ }^{32)}$. Higher c-reactive protein or white blood cells, which represent sub-clinical inflammatory processes, are associated with high GGT levels ${ }^{24)}$. GGT also plays a direct role in LDL oxidation by hydrolyzing glutathione into more potent iron reductants ${ }^{33)}$, and has an indirect role as a marker in antioxidant systems by maintaining the intracellular concentration of glutathione in response to oxidative stress ${ }^{34)}$.

Some limitatons of this study must be considered. First, our cross-sectional study design does not eliminate potential causal relationships between GGT and MetS. There remain important questions about the cumulative effects of these CVD risk factors over several decades and the interactions with other risk factors. Second, the prevalence of MetS and GGT categories is based on a single assessment of blood, which may introduce a misclassification bias. Third, we used $\mathrm{BMI} \geqq 25$ to classify individuals with visceral obesity because waist circumference measurements were not available, which might have underestimated the effect of visceral obesity on $\mathrm{Met} \mathrm{S}^{35}$. Fourth, the presence of viral hepatitis must be considered, but examinations of hepatitis B surface antigen and the antibody to hepatitis $\mathrm{C}$ were not performed; therefore, the demographics and referral source may limit generalizability.

In conclusion, the present study showed that serum GGT levels are strongly associated with MetS 
or its components in the general population. The underlying mechanism behind this relationship is unclear, but seems to be independent of traditional cardiovascular risk factors, such as age, smoking status, drinking status, LDL-C, uric acid, or renal function. For community-dwelling healthy individuals, prospective population-based studies are needed to investigate the mechanisms underlying this association to determine whether intervention, such as effective lifestyle modifications that decrease GGT in adults, will decrease MetS risks.

\section{Acknowledgement}

This work was supported in part by a grant-inaid from the Foundation for the Development of Community (2008).

\section{References}

1) Whitfield JB: Gamma glutamyl transferase. Crit Rev Clin Lab Sci, 2001; 38:263-355

2) Emdin M, Pompella A, Paolicchi A: Gamma-glutamyl transferase, atherosclerosis, and cardiovascular disease: triggering oxidative stress within the plaque. Circulation, 2005; 112:2078-2080

3) Lee DH, Silventoinen K, Hu G, Jacobs DR Jr, Jousilahti P, Sundvall J, Tuomilehto J: Serum gamma-glutamyltransferase predicts non-fatal myocardial infarction and fatal coronary heart disease among 28,838 middle-aged men and women. Eur Heart J, 2006; 27:2170-2176

4) Meisinger C, Döring A, Schneider A, Löwel H; KORA Study Group: Serum gamma-glutamyltransferase is a predictor of incident coronary events in apparently healthy men from the general population. Atherosclerosis, 2006; 189:297-302

5) Shankar A, Li J, Klein BE, Javier Nieto F, Klein R: Serum gamma-glutamyltransferase level and peripheral arterial disease. Atherosclerosis, 2008; 199:102-109

6) Poikolainen K, Vartiainen E: Determinants of gammaglutamyl transferase: positive interaction with alcohol and body mass index, negative association with coffee. Am J Epidemiol, 1997; 146:1019-1024

7) André P, Balkau B, Born C, Charles MA, Eschwège E; D.E.S.I.R study group: Three-year increase of gamma-glutamyltransferase level and development of type 2 diabetes in middle-aged man and women: the D.E.S.I.R cohort. Diabetologia, 2006; 49:2599-2603

8) André P, Balkau B, Vol S, Charles MA, Eschwège E; DESIR Study Group: Gamma-glutamyltransferase activity and development of the metabolic syndrome (International Diabetes Federation Definition) in middle-aged men and women: Data from the Epidemiological Study on the Insulin Resistance Syndrome (DESIR) cohort. Diabetes Care, 2007; 30:2355-2361

9) Lee DH, Jacobs DR Jr, Gross M, Kiefe CI, Roseman J, Lewis CE, Steffes M: Gamma-glutamyltransferase is a predictor of incident diabetes and hypertension: the Coronary Artery Risk Development in Young Adults (CARDIA) Study. Clin Chem, 2003; 49:1358-1366

10) Nakanishi N, Suzuki K, Tatara K: Serum gamma-glutamyl transferase and risk of metabolic syndrome and type 2 diabetes in middle-aged Japanese men. Diabetes Care, 2004; 27:1427-1432

11) Shankar A, Li J: Association between serum gamma-glutamyl transferase level and prehypertension among US adults. Circ J, 2007; 71:1567-1572

12) Rantala AO, Lilja M, Kauma H, Savolainen MJ, Reunanen A, Kesäniemi YA: Gamma-glutamyl transpeptidase and the metabolic syndrome. J Intern Med, 2000; 248:230-238

13) Sakugawa H, Nakayoshi T, Kobashigawa K, Nakasone $H$, Kawakami Y, Yamashiro T, Maeshiro T, Tomimori K, Miyagi S, Kinjo F, Saito A: Metabolic syndrome is directly associated with gamma glutamyl transpeptidase elevation in Japanese women. World J Gastroenterol, 2004; 10:10521055

14) Lee DS, Evans JC, Robins SJ, Wilson PW, Albano I, Fox CS, Wang TJ, Benjamin EJ, D’Agostino RB, Vasan RS: Gamma glutamyl transferase and metabolic syndrome, cardiovascular disease, and mortality risk: the Framingham Heart Study. Arterioscler Thromb Vasc Biol, 2007; 27:127-133

15) Kekeuchi H, Saitoh S, Takagi S, Ohnishi H, Ohata J, Isobe T, Fujiwara T, Akasaka K, Shimada K: Metabolic syndrome and insulin resistance in Japanese Male-TannoSoubetsu Study. J Japan Diab Soc, 2003; 46:739-744 (in Japanese, Abstract in English)

16) Shiwaku K, Nogi A, Kitajima K, Anuurad E, Enkhmaa B, Yamasaki M, Kim JM, Kim IS, Lee SK, Oyunsuren T, Yamane Y: Prevalence of the metabolic syndrome using the modified ATPIII definitions for workers in Japan, Korea and Mongolia. J Occup Health, 2005; 47:126-135

17) Lorenzo C, Okoloise M, Williams K, Stern MP, Haffner SM; San Antonio Heart Study: The metabolic syndrome as predictor of type 2 diabetes: the San Antonio heart study. Diabetes Care, 2003; 26:3153-3159

18) McNeill AM, Rosamond WD, Girman CJ, Golden SH, Schmidt MI, East HE, Ballantyne CM, Heiss G: The metabolic syndrome and 11-year risk of incident cardiovascular disease in the atherosclerosis risk in communities study. Diabetes Care, 2005; 28:385-390

19) Lakka HM, Laaksonen DE, Lakka TA, Niskanen LK, Kumpusalo E, Tuomilehto J, Salonen JT: The metabolic syndrome and total and cardiovascular disease mortality in middle-aged men. JAMA, 2002; 288:2709-2716

20) Friedewald WT, Levy RI, Fredrickson DS: Estimation of the concentration of low-density lipoprotein cholesterol in plasma, without use of the preparative ultracentrifuge. Clin Chem, 1972; 18:499-502

21) The Japanese Society of Nephrology: Japanese version of GFR estimation. http://www.jsn.or.jp, 2007; Updated Oct 29

22) Matthews DR, Hosker JP, Rudenski AS, Naylor BA, Treacher DF, Turner RC: Homeostasis model assessment: insulin resistance and beta-cell function from fasting plasma glucose and insulin concentrations in man. Diabetologia, 1985; 28:412-419 
23) Examination committee of criteria for diagnosis of metabolic syndrome in Japan: Definition and criteria for the diagnosis of metabolic syndrome. J Jpn Soc Int Med, 2005; 94:794-809 (in Japanese, Abstract in English)

24) The examination Committee of Criteria for "Obesity Disease" in Japan: Japan Society for Study of Obesity. New criteria for 'obesity disease' in Japan. Circ J, 2002; 66:987-992

25) Ota T, Takamura T, Hirai N, Kobayashi K: Preobesity in World Health Organization classification involves the metabolic syndrome in Japanese. Diabetes Care, 2002; 25:1252-1253

26) Inoue K, Hirohara J, Nakano T, Seki T, Sasaki H, Higuchi K, Ohta Y, Onji M, Muto Y, Moriwaki H: Prediction of prognosis of primary biliary cirrhosis in Japan. Liver, $1995 ; 15: 70-77$

27) Lee DH, Ha MH, Kim KY, Jin DG, Jacobs DR Jr: Gamma-glutamyltransferase: an effect modifier in the association between age and hypertension in a 4-year follow-up study. J Hum Hypertens, 2004; 18:803-807

28) Kang YH, Min HK, Son SM, Kim IJ, Kim YK: The association of serum gamma glutamyltransferase with components of the metabolic syndrome in the Korean adults. Diabetes Res Clin Pract, 2007; 77:306-313

29) Ikai E, Honda R, Yamada Y: Serum gamma-glutamyl transpeptidase level and blood pressure in nondrinkers: a possible pathogenetic role of fatty liver in obesity-related hypertension. J Hum Hypertens, 1994; 8:95-100

30) Nilssen O, Førde OH: Seven-year longitudinal population study of change in gamma-glutamyltransferase: the Tromsø Study. Am J Epidemiol, 1994; 139:787-792

31) Hotamisligil GS: Inflammatory pathways and insulin action. Int J Obes Relat Metab Disord, 2003; 27 Suppl 3:S53-S55

32) Fain JN: Release of interleukins and other inflammatory cytokines by human adipose tissue is enhanced in obesity and primarily due to the nonfat cells. Vitam Horm, 2006; 74:443-477

33) Paolicchi A, Minotti G, Tonarelli P, Tongiani R, De Cesare D, Mezzetti A, Dominici S, Comporti M, Pompella A: Gamma-glutamyl transpeptidase-dependent iron reduction and LDL oxidation--a potential mechanism in atherosclerosis. J Investig Med, 1999; 47:151-160

34) Karp DR, Shimooku K, Lipsky PE: Expression of gammaglutamyl transpeptidase protects ramos B cells from oxidation-induced cell death. J Biol Chem, 2001; 276:37983804

35) Kawamoto R, Ohtsuka N, Ninomiya D, Nakamura S: Carotid atherosclerosis in normal-weight metabolic syndrome. Intern Med, 2007; 46:1771-1777 